\title{
Paulo Henriques Britto, desleitor de João Cabral
}

\author{
ANTONIO CARLOS SECCHIN ${ }^{I}$
}

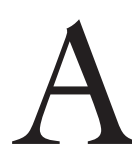

ESTREIA de Paulo Henriques Britto (1989), com Liturgia da matéria, já continha um ingrediente básico de toda a sua poesia: o jogo tenso entre acolhimento e recusa do legado de João Cabral, por meio de sutis operações que captam e reprocessam em desleitura alguns traços marcantes do poeta pernambucano. Nesse sentido, a obra de Britto acabará, em parte, sendo tecida contra a cabralina, sem que o contra implique hostilidade; trata-se de deslocamentos e desestabilizações de matriz altamente considerada no interior do dissídio. Bem diferente, por exemplo, da oposição movida, na década de 1970, por vários nomes da geração marginal, para quem João Cabral foi autor descartado, e igualmente diverso do acolhimento acrítico por parte dos subcabrais que cerebrinamente lhe copiavam os procedimentos mais explícitos. Nesse panorama, cindido entre os "espontâneos" e os "afilhados da vanguarda”, a voz inicial de Paulo Henriques já soava com desassombrado talento e individualidade.

Se, como supomos, Britto lê e deslê João, importa assinalar certas afinidades entre ambos, para a seguir percebermos a demarcação de diferenças. $\mathrm{Na}$ contramão do discurso atomizado na linhagem da poesia-minuto, ambos são poetas da sintaxe, vale dizer, neles a poesia reside antes no processo da construção do que no fulgor ocasional de um verso. O primeiro e o sétimo dos "Dez sonetos sentimentais", de Britto, desdobram-se num solitário período gramatical. O texto seccionado em segmentos numerados e vazado em quadras (cf. "Elogio do mal") também é constante em Cabral, bem como a prática da métrica regular e das formas fixas. Nos sonetos, Paulo Henriques tende a mostrar-se mais ortodoxo no campo da métrica, fazendo incidir no decassílabo as usuais cesuras em quarta ou sexta sílaba, ao passo que João, no verso longo, abdica das marcações rítmicas do heroico e do sáfico e tece variações entre nove e onze sílabas, sem, todavia, renunciar à rima, toante. Em Britto, por seu turno, a utilização da rima, nos livros iniciais, é esporádica, em prol dos versos brancos.

Mas, paralelas aos aspectos da técnica versificatória (crucial para os dois poetas), avultam diferentes estratégias para urdir o esvaziamento do sujeito lírico. João Cabral se vale de recursos explícitos, na sempre referida busca da “objetividade", ao subtrair de cena a primeira pessoa do singular. A poesia de Britto, aparentemente, investe no oposto, encharcando-se de subjetividade.

Examinada de perto, contudo, a questão está longe de ser tão simples assim, de um e outro lado. Certas obsessões cabralinas duplicam-se nos seres e 
situações que as representam; de certo modo, eles e elas compõem um sistemático, posto que oblíquo, retrato do artista, chegando-se portanto, por meio dos tais objetos de eleição, à elaboração de uma autobiografia em terceira pessoa: "eles" são "eu". Em Paulo Henriques Britto, ao contrário, inexistem vetores de estabilidade que constituam imagem sólida de uma persona poética: "eu" não sou "eu". Se Cabral mostra-se coeso e coerente por sob o véu dos outros a que delegou poder de representação (o sol, a seca, a pedra), Britto elabora uma "autobiografia desautorizada", divagações de um "eu” (e de um "tu” também, inconstante e amável leitor) em perpétuo descrédito. Incisivas doses de autoironia impedem a cristalização de crenças e apontam a fragilidade de projetos alicerçados na falácia da unidade do sujeito. Conforme dirá no segundo dos "Sete sonetos simétricos", de Macau (Britto, 2003, p.42), tudo é irrisório, quando circunscrito ao "cais úmido e ínfimo do eu".

Em Liturgia da matéria (Britto, 1989), três poemas parecem responder quase pontualmente a incitações cabralinas. No ano de 1947, João Cabral de Melo Neto (2008, p.69) escrevera, na Psicologia da composição: "Esta folha branca / me proscreve o sonho"; Paulo Henriques replica, na "Logística da composição": "Só o sonho é inevitável" (Britto, 1989, p.39). Na mesma direção, "Persistência do sonho" evoca "névoa densa e teimosa / que não há sol que a dissolva" (ibidem, p.56), enquanto Melo Neto (2008, p.335), "Num monumento à aspirina", elogiava o medicamento por constituir-se no "mais prático dos sóis" e assim dissipar os borrões do entorno, propiciando um clima "cartesiano". Os complexos raciocínios do poeta pernambucano desenvolvidos em "Rios sem discurso" e "Os rios de um dia" encontram revide em "Dos rios", de Britto (1989, p.64): "os rios foram feitos pra fugir, / fluir, não para analisar".

Um gesto interlocutório sem subterfúgios ocorre em "Indagações" (de Mínima lírica, Britto, 1989), cuja parte inicial intitula-se "Para João Cabral". Em 1985, o poeta pernambucano publicara em Agrestes o texto-homenagem "Dúvidas apócrifas de Marianne Moore", com o qual o poema de Britto estabelece sofisticado diálogo de formas. Senão, constatemos: nos títulos dos dois textos comparece o nome de outro poeta; ambos contêm quatro estrofes; as terceiras e quartas encerram-se igualmente em pontos de interrogação; o substantivo "coisa", no singular ou no plural, surge no verso 1 das duas terceiras estâncias, e o advérbio "não" abre as respectivas estrofes 2 . Por fim (ou no começo), os dois poemas partem de versos bastante próximos, uma espécie de mote do que na sequência se lerá. Em Paulo Henriques Britto (1989, p.88): "Não escrever sobre si". Em João Cabral de Melo Neto (2008, p.522): "Sempre evitei falar de mim".

Em "Dois amores rápidos" - "Dar tanto, tanto/ para dar no que deu. // Pensando bem, / o errado fui eu. // Mas já que terminou,/ adeus" (Britto, 1989, p.83 ) - assoma o veio lírico e sintético, de fatura e humor leminskianos, inexistente em Cabral, cuja impregnação, porém, é nítida nos quatro belos sonetos em decassílabos rimados de "Mínima poética". O primeiro registra: "Palavra 
como lâmina só gume / que pelo que recorta é recortada, / .../ a fala - esquiva, oblíqua, angulosa - / do que resiste à retidão da prosa” (ibidem, p.90). Para além da clara evocação de Uma faca só lâmina (de 1956), destaca-se imagem aparentada à de "Menino de engenho" (1980), de João Cabral de Melo Neto (2008, p.391): “A cana cortada é uma foice. / Cortada num ângulo agudo / ganha o gume afiado da foice / que a corta em foice, um dar-se mútuo". No soneto 2 há sentidos contrastivos: Cabral, diversas vezes, elogiou o caráter duro e incorruptível da pedra, sua frieza e densidade, enquanto Britto (1989, p.91) parece replicar: "A pedra só é bela, embora dura / se meu desejo em torno dela tece / uma carne de sentido, e acredita / que desse modo abranda e amolece". O terceiro soneto, endosso da potência do verbo, mas repúdio à sua fetichização, ataca a intransitividade da metalinguagem, por meio de léxico aparentado ao cabralino "A palo seco", então relido, em alguns tópicos, num viés de recusa. Paulo Henriques Britto (1989, p.92) invectiva a "forma subversa, insignificante, / [que] se fecha em não - canto sem quem o cante", ao passo que Cabral de Melo Neto (2008, p.226) louvara "o cante sem mais nada", o "cante que não canta". Por fim, no soneto 4, Britto (1989, p.93) associa escrever a "pintar, mas não como aquele que pinta / de branco o muro que já foi caiado"; João Cabral de Melo Neto (2008, p.202), em "Paisagem pelo telefone", destacara o branco de "muros caiados", de algum modo tornados ainda mais alvos pela luz do sol que neles incidia.

O livro seguinte, Trovar claro (Britto, 1997), comporta peças com a marca da rima toante, obsessiva em Cabral: assim "O prestidigitador", o primeiro dos "Dois noturnos". O ideal de um mundo nítido e ordenado, tão patente em João desde "O engenheiro" - "O engenheiro sonha coisas claras: / superfícies, tênis, um copo de água. / / O engenheiro pensa o mundo justo / mundo que nenhum véu encobre" (ibidem, p.46) é solapado pelo "Idílio" henriquiano, que, após simular a adesão aos valores da ordem e da transparência - "Desejo de formas claras e puras / de nitidezes simples, minerais, / certezas retilíneas como agulhas" - acaba associando-os ao abafamento da pulsação e da nervura da existência: "Nada de nebuloso, frouxo ou úmido /.../ sem olhos malcheirosos e carnais. / O sonho quer estrangular o mundo" (ibidem, p.77) - o sonho da razão imperativa, entenda-se. Paulo Henriques Britto acolhe e acalenta o espaço da imprecisão, ainda que seja rigoroso no gesto de formulá-lo. Como dirá em "História natural" (título, aliás, homônimo à peça cabralina), o sujeito almeja "a forma exata da sombra difusa" (Britto, 1997, p.83).

As obras subsequentes darão continuidade ao diálogo crítico entre incorporação e recusa do legado de Cabral. A Psicologia da composição, conforme vimos, antes já transformada em "logística", é reapropriada como "Fisiologia da composição", em Macau (Britto, 2003). Suas partes encontram-se separadas e sequenciadas por algarismos romanos, recurso similar ao da Psicologia de João. O dissenso, porém, já irrompe na declaração anticabralina que arremata 
o segmento I: "Por fim o acaso. / Sem o qual, nada” (ibidem, p.13). O poeta recifense sempre tentou minimizar a importância do acaso em sua produção. No desfecho da Fábula de Anfion (1947), o protagonista prefere silenciar a render-se ao poder sem controle da criação. Alguns traços do cabralino "Tecendo a manhã" (1966) reaparecem, difusos, na parte V da "Fisiologia": nos dois se evoca a construção de um objeto, o balão-poema, e o esforço para fazê-lo decolar. "Estrutura”, “coisa sólida”, “artificial”, signos recorrentes em Cabral, surgem para serem sutilmente ironizados no desígnio final do texto-balão de Britto (2003, p.17), que demanda "Menos arquitetura / que balística. É claro que é difícil”. Em "Bagatela para a mão esquerda”, de Paulo Henriques, e "O sim contra o sim" (1960), de João Cabral, porém, ambos os poetas se irmanam no endosso ao poder criador que ultrapassa a maestria automatizada: "A esquerda ( se não se é canhoto) / é mão sem habilidade; / reaprende a cada linha, / a cada instante, a recomeçar-se” (Melo Neto, 2008, p.274); “À mão esquerda é vedado / o recurso falso e fácil / de dispensar partitura, / a fraqueza (dita força)/ do hábito) (Britto, 2003, p.19).

No livro Tarde (Britto, 2007), o já citado "Num monumento à aspirina” é reprocessado em "Para um monumento ao antidepressivo". Enquanto o texto cabralino celebra o efeito do medicamento, o de Britto $(2007$, p.63) atenta para o fato de que o alívio momentâneo somente mascara a revelação “dura, doída” da "humana condição".

Finalmente, Formas do nada (Britto, 2012, p.42) releva, em "Fábula", o fértil poder do improviso e do acaso (tão duramente repelido na "Fábula de Anfion" cabralina), em confronto com o impasse estéril e autofágico da mentação excessiva: "Um pensamento pensado / até a total exaustão / termina por germinar / no mesmo exato lugar / sua exata negação. / / Enquanto isso uma ideia/ trauteada numa flauta/ faz uma cidade erguer-se - / é claro, sem alicerces,/ mas ninguém dá pela falta”.

A João Cabral de Melo Neto (2008, p.68) incomodava o soar aleatório da flauta ("Uma flauta: como/ dominá-la, cavalo / solto que é louco?"); em Paulo Henriques Britto não há como descer desse cavalo, ainda que não saiba direito para onde aquilo tudo - o poema, a vida - conduz. Enquanto um poeta sinaliza a poética do "não", da contenção e do silêncio, o outro, em Trovar claro, aconselha, desabusado: “Escreve, escreve até estourar. E tome valsa” (Britto, 1997, p.85).

Referências

BRITTO, P. H. Mínima lírica; Liturgia da matéria. São Paulo: Duas Cidades, 1989.

. Trovar claro. São Paulo: Cia. das Letras, 1997.

. Macau. São Paulo: Cia. das Letras, 2003.

. Tarde. São Paulo: Cia. das Letras, 2007. 
BRITTO, P. H. Formas do nada. São Paulo: Cia. das Letras, 2012.

MELO NETO, J. C. de. Poesia completa e prosa. 2.ed Rio de Janeiro: Nova Aguilar, 2008.

Antonio Carlos Secchin é doutor em Letras e professor titular de Literatura Brasileira da Universidade Federal do Rio de Janeiro (UFRJ). Poeta e ensaísta com vários livros publicados, é membro da Academia Brasileira de Letras. @ - acsecchin@uol.com.br Recebido em 22.10.2014 e aceito em 10.11.2014.

${ }^{\text {I }}$ Universidade Federal do Rio de Janeiro, Rio de Janeiro/Rio de Janeiro, Brasil. 
